\title{
5 \\ Efficiency and Accuracy of Importing HEC-RAS Datafiles into PCSWMM and SWMM5
}

\author{
Karen Finney, Rob James, William James and Tiehong Xiao
}

An advantage of USEPA's SWMM5 is its capability to dynamically model complex watersheds that include, among other things, negative slopes and parallel or looped links (Rossman, 2008). SWMM5 models have been used for a variety of watershed applications including flood inundation and flood forecasting, and SWMM5 is accepted for floodway and floodplain determination by the Federal Emergency Management Agency (FEMA). HEC-RAS (Hydrologic Engineering Centers River Analysis System; U.S. Army Corps of Engineers, 2010) is widely accepted for floodplain management studies, and commonly used to delineate flood lines (Federal Emergency Management Agency, 2002). HEC-2, last released in 1991, was the predecessor of HEC-RAS.

Both SWMM5 and HEC-RAS solve numerical formulations of the continuity and momentum equations simultaneously in space, and stepwise in time, over an arbitrary drainage network. Together the equations are known as the Saint-Venant or dynamic wave equations. The primary difference between the two models is that SWMM5 includes routines that account for the engineered infrastructure in both urban and rural hydrology and hydraulics, whereas HEC-RAS simulates only the hydraulics components of a rural watershed. HEC-RAS represents natural open channels only, as a link-node network in which conduits are rectilinear and prismoidal, varying linearly in cross section from one transect (node) to the next. On the other hand, SWMM5 represents all types of conduits, open and closed, as uniform, rectilinear and prismoidal, with constant cross section between the nodes (usually denoted junctions),

Finney, K., R. James, W. James and T. Xiao. 2013. "Efficiency and Accuracy of Importing HEC-RAS Datafiles into PCSWMM and SWMM5." Journal of Water Management Modeling R246-05. doi: 10.14796/JWMM.R246-05.

(C) CHI 2013 www.chijournal.org ISSN: 2292-6062 (Formerly in Pragmatic Modeling of Urban Water Systems. ISBN: 978-0-9808853-8-5) 
which may be storage or treatment devices. Links may be pumps, orifices, weirs or regulators. HEC-RAS is not commonly used to model unsteady flow conditions, whereas SWMM5 is usually used to model gradually varied flow conditions.

Another difference between HEC-RAS and SWMM5 lies in how bridges and culverts are represented. In HEC-RAS, bridges are defined using four cross sections to compute energy losses:

1. The downstream location where flow has fully expanded (no longer affected by the bridge);

2. The downstream cross section immediately downstream from the bridge, giving the narrowest shape in the expansion zone;

3. The cross section immediately upstream from the bridge, depicting the narrowest part of the contraction zone; and

4. The upstream location where flow has not yet contracted into the bridge structure (U.S. Army Corps of Engineers, 2010).

SWMM5 does not model bridges explicitly; instead it represents waterway structures using one or more parallel custom conduit shapes and high cord conduits positioned parallel to one another. In these equivalent conduits the complete Saint-Venant flow equations can be solved using dynamic wave routing.

Many river and stream studies have been conducted using HEC-2 or HEC-RAS and steady state flows. Thus copious HEC-RAS and HEC-2 data are available and are used in current watershed studies. Until recently, importing HEC-2 and HEC-RAS data into SWMM5 involved manually importing cross sections and converting the available flow area under a bridge (accounting for the pier structures) into equivalent conduit cross sections. Depending on the number of transects and bridges in the studied river reaches, this process can be both time consuming and error prone.

For these reasons, PCSWMM 2011 (a spatial group decision support system for SWMM5 for stormwater management, wastewater and watershed modeling) has been enhanced to efficiently create SWMM5 dynamic wave models from HEC-RAS geometric files. This new HEC-RAS importer code in PCSWMM is described below, and a comparison of HEC-RAS and SWMM5 computed water surface elevations is presented.

\subsection{SWMM5 Flow Routing Options}

For hydraulic routing of flood waves in water courses, SWMM5 incorporates steady state, kinematic wave and dynamic wave routing methods. Of these, dynamic wave routing is recommended because the steady state and kinematic 
wave options do not permit negative slopes, parallel links or flow splits in the downstream direction. Moreover, only the dynamic wave option can simultaneously handle surcharged and pressurized flow, dynamically varying inlet and outlet control, reverse flow and backwater effects (James et al., 2011).

PCSWMM options for importing a HEC-RAS data file allow several levels of detail as well as the routing method. The main difference between dynamic, as opposed to kinematic or steady state, methods lies in how bridge and culvert structures are represented.

\subsubsection{Rivers and Reaches}

In HEC-RAS, river networks are identified by assigning river and reach names that are defined by a junction. Rivers are identified by unique names and can have multiple associated reaches. Cross sections containing station or elevation data are positioned along a reach. In SWMM5, the hydraulic characteristics of each link are defined by a uniform transect (cross section); the node provides the required vertical detail.

\subsubsection{Geo-referencing Data}

When importing a HEC-RAS model data into PCSWMM, geo-referencing data is acquired from the river and reach centerlines, cross sectional (transect) cut lines, and reach junctions. The following paragraphs describe how HECRAS modeling data is converted into SWMM5.

\section{Transects}

Transect or cross sectional data, including roughness values and bank stations, are imported from HEC-RAS cross sectional data. Figure 5.1 shows the representation of transect (SWMM5) and cross sectional (HEC-RAS) editors in PCSWMM and HEC-RAS.

\section{Junctions}

Junctions are stationed at the location of each transect using geo-referencing data. Junction depths and invert elevations are based on the transect cross section maximum and minimum elevations.

\section{Conduits}

Conduits are drawn based on HEC-RAS river centerlines. Imported cross sections are assigned to the downstream SWMM5 conduits as irregular open channel transects. The lengths of the conduits are imported from the cross sectional data. 


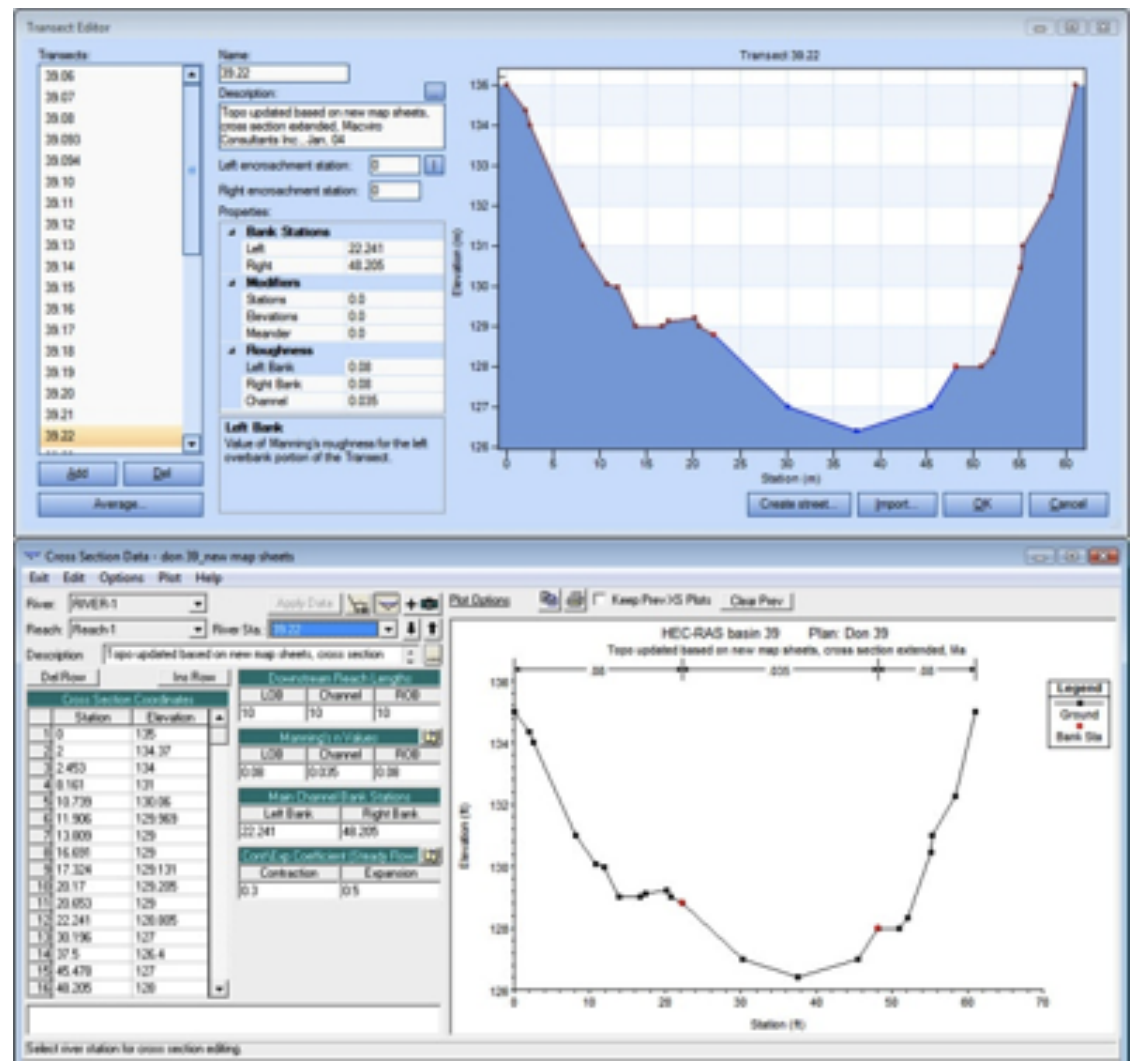

Figure 5.1 Cross sectional data comparison: PCSWMM-SWMM5 (top) and HEC-RAS (bottom).

\section{Culverts}

Common culvert cross sectional shapes are imported from the culvert data editor into the conduit cross section attribute. SWMM5 recognizes and supports most culvert shapes

\section{Bridges}

There are multiple options when importing bridges into PCSWMM including: creating multiple conduits for bridge piers and creating high-chord transects. The first method is to create multiple conduits. This method creates a custom shape curves for each bridge opening. Figure 5.2 shows is an example of a HEC-RAS bridge with five piers. In this case, the HEC-RAS importing tool would generate six custom shape curves representing the cross sectional area between each pier. This method of importing bridges can only be applied to models that are to be run using dynamic wave routing, as kinematic and steady state routing do not allow parallel conduits. 


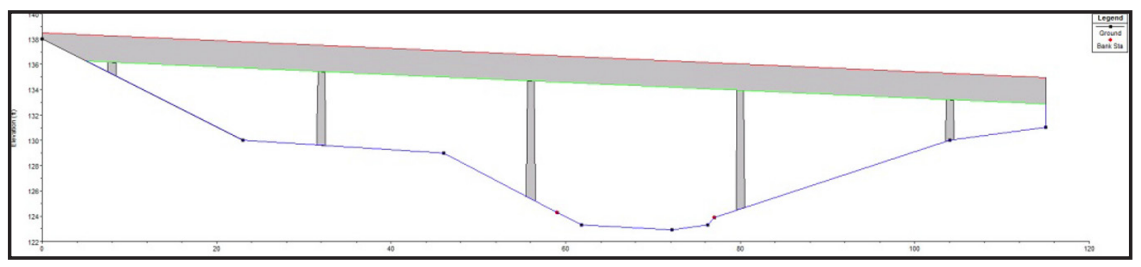

Figure 5.2 Bridge shown in HEC-RAS with 5 piers.

When overtopping is of concern, the bridge or culvert high chord can be imported as a transect and represented as a parallel irregular conduit.

\subsubsection{Using Geo-Reference to Locate Junctions}

In HEC-RAS the distances between cross sections, defined in the cross section editor, do not necessarily match the GIS distance between cross sections.

When importing a HEC-RAS model, the user can optionally select to use geo-referencing to locate junctions. This positions the junctions based on the geo-referenced location, as displayed in the HEC-RAS geometric window, instead of the user defined lengths. The user defined lengths can also be replaced by the GIS lengths once the HEC-RAS model is imported.

Accurate geo-referencing is important for SWMM5 flood line analysis, combined 1D-2D analysis and any application that uses digital elevation model (DEM) data as part of the model analysis. Geo-referencing also allows the user to create compelling presentations by projecting the SWMM5 model into Google Earth.

\subsection{HEC-RAS and PCSWMM HGL Comparison}

To determine if SWMM5 was able to compute results comparable to those generated in HEC-RAS, a HEC-RAS model was imported into two SWMM5 models. The first model was set up to run using kinematic wave routing while the second model used dynamic wave routing. For the kinematic model the bridge was represented with a custom culvert that accounted for the surface area available for flow at defined elevations.

The HEC-RAS model selected represented a section of the Don River watershed, referred to as basin 39A, and is located mainly north of Toronto, Ontario. This section consisted of $\sim 4 \mathrm{~km}$ river and had three bridge structures. The location of basin 39A can be seen in Figure 5.3. The computed HECRAS peak surface water elevations, run as steady state, were compared using a 100 y event for the Don River watershed. 


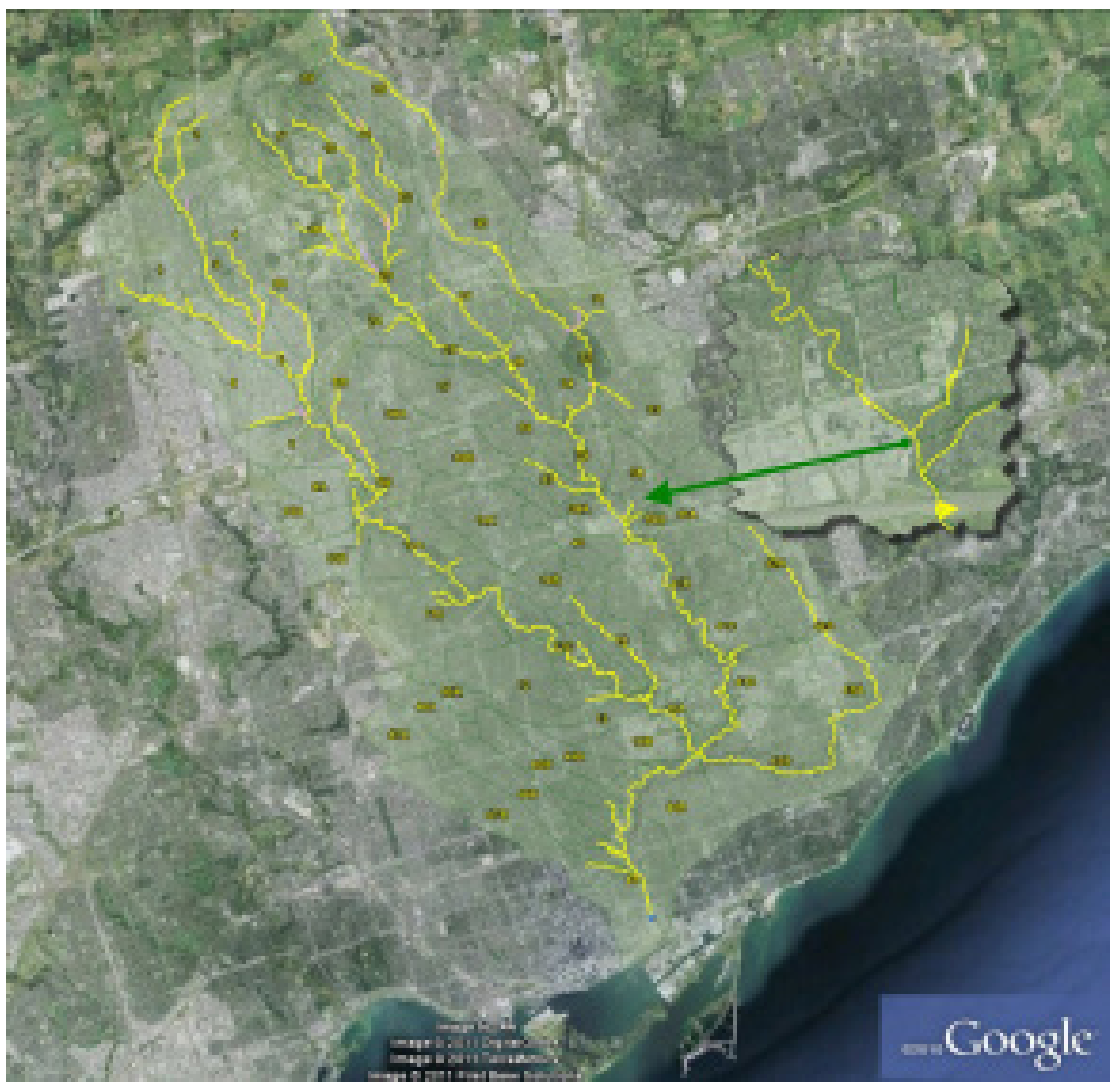

Figure 5.3 Location of HEC-RAS model section located in the Don River watershed in Ontario.

\subsubsection{HEC-RAS and SWMM5 100 y HGL Comparison}

An important difference between HEC-RAS and SWMM5 is in how the programs interpret the assigned baseline flows. In HEC-RAS, the assigned flow rate supersedes any steady flow rates assigned upstream (U.S. Army Corps of Engineers, 2010).

In SWMM5, the baseline flows assigned to the nodes represent additional inflow; instead of replacing the previous flow with the new flow, the program adds the new flow to the previous flow. Thus, to set similar conditions as a steady state HEC-RAS model, SWMM5 baseline flows need only to be entered at the upstream junctions. Figure 5.4 shows a screenshot of the steady flow data assigned to the basin 39A HEC-RAS model. 


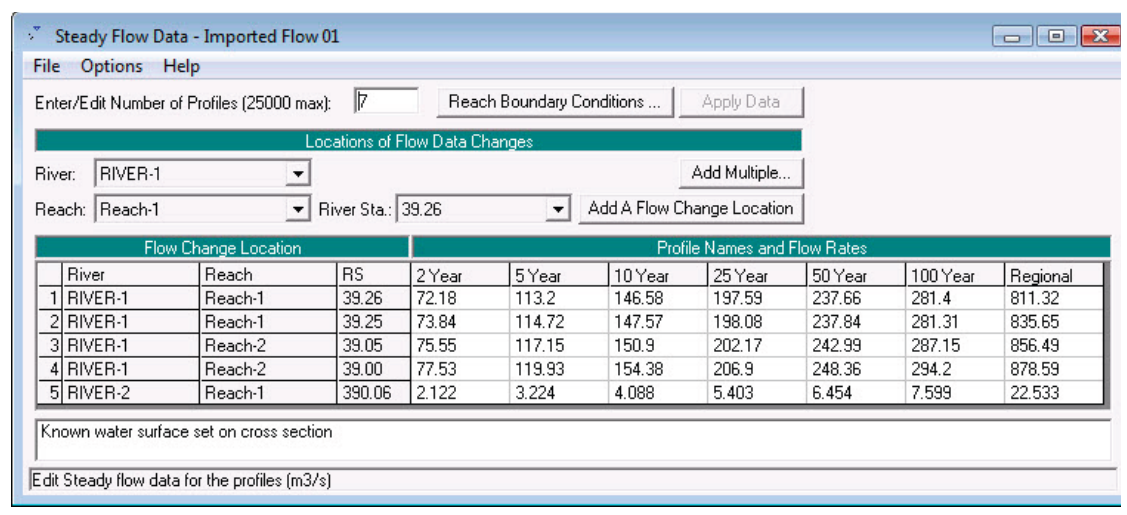

Figure 5.4 Steady state inputs for the HEC-RAS model.

In order to represent the HEC-RAS baseline in SWMM5, the upper junctions were assigned with flow values of $281.4 \mathrm{~m}^{3} / \mathrm{s}$ for reach 1 (J36.26) and $7.6 \mathrm{~m}^{3} / \mathrm{s}$ for reach $2(\mathrm{~J} 390.06)$. Figure 5.5 provides reference to the branch locations.

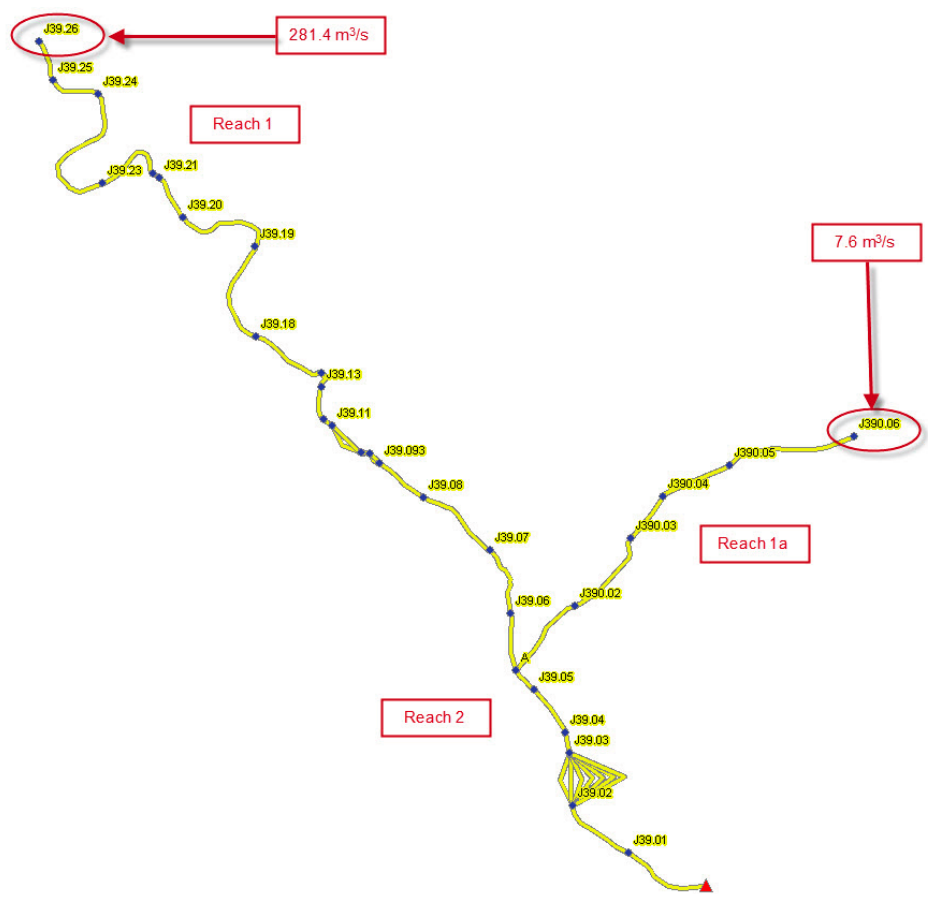

Figure 5.5 Baseline flow locations (junctions J39.26 and J390.06). 
The results comparing the kinematic and dynamic routing to the HECRAS peak water surface elevation are shown in Figure 5.6. The results of the kinematic SWMM5 model did not show a strong comparison and there is a lot of scatter in the data. In contrast, the HGL results simulated using dynamic wave routing compared closely to the HEC-RAS steady state results with an $R^{2}$ value of 0.98 .

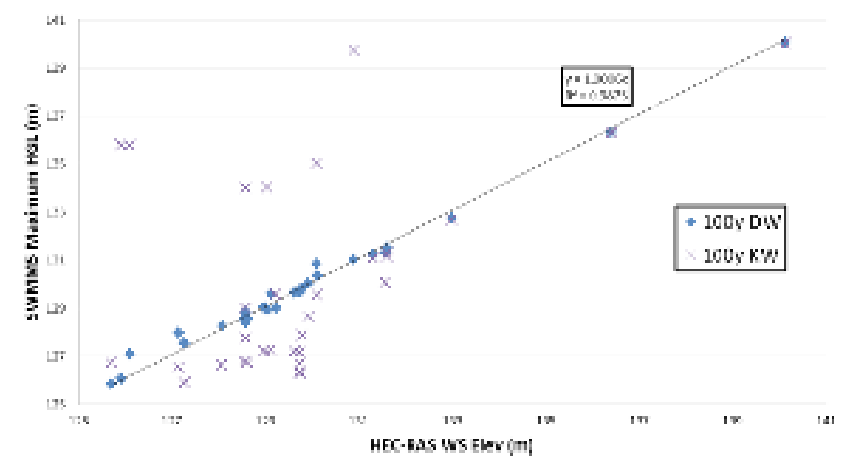

Figure 5.6 Hydraulic grade line (HGL) comparison SWMM5 dynamic wave and kinematic wave

A second comparison was performed to observe the HGL comparison separately for the three branches in the model where reach 1 had an $R^{2}$ value of 0.94 , reach $1 \mathrm{~A}$ had an $R^{2}$ value of 0.999 and reach 2 had an $R^{2}$ value of 0.86 . Figure 5.7 shows the locations of the three branches within basin 39A.

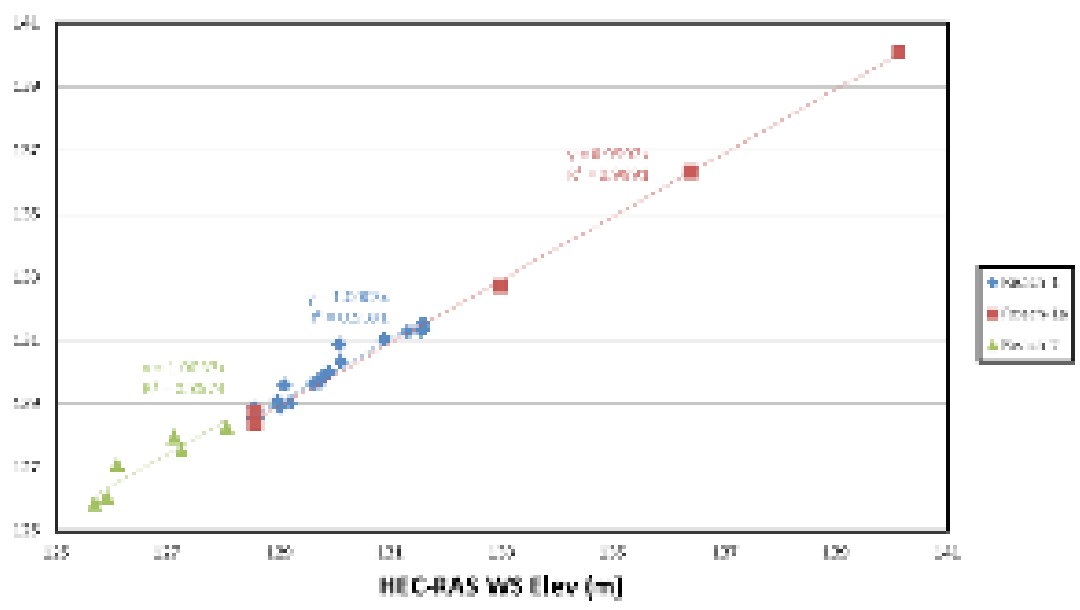

Figure 5.7 Hydraulic grade line (HGL) comparison SWMM5 vs HECRAS 100 y showing the HGL comparisons for each of the three locations. 
The depth discrepancies can be attributed primarily to losses resulting from differences in bridge representations between HEC-RAS and SWMM5.

\subsubsection{Main Channel Discrepancies}

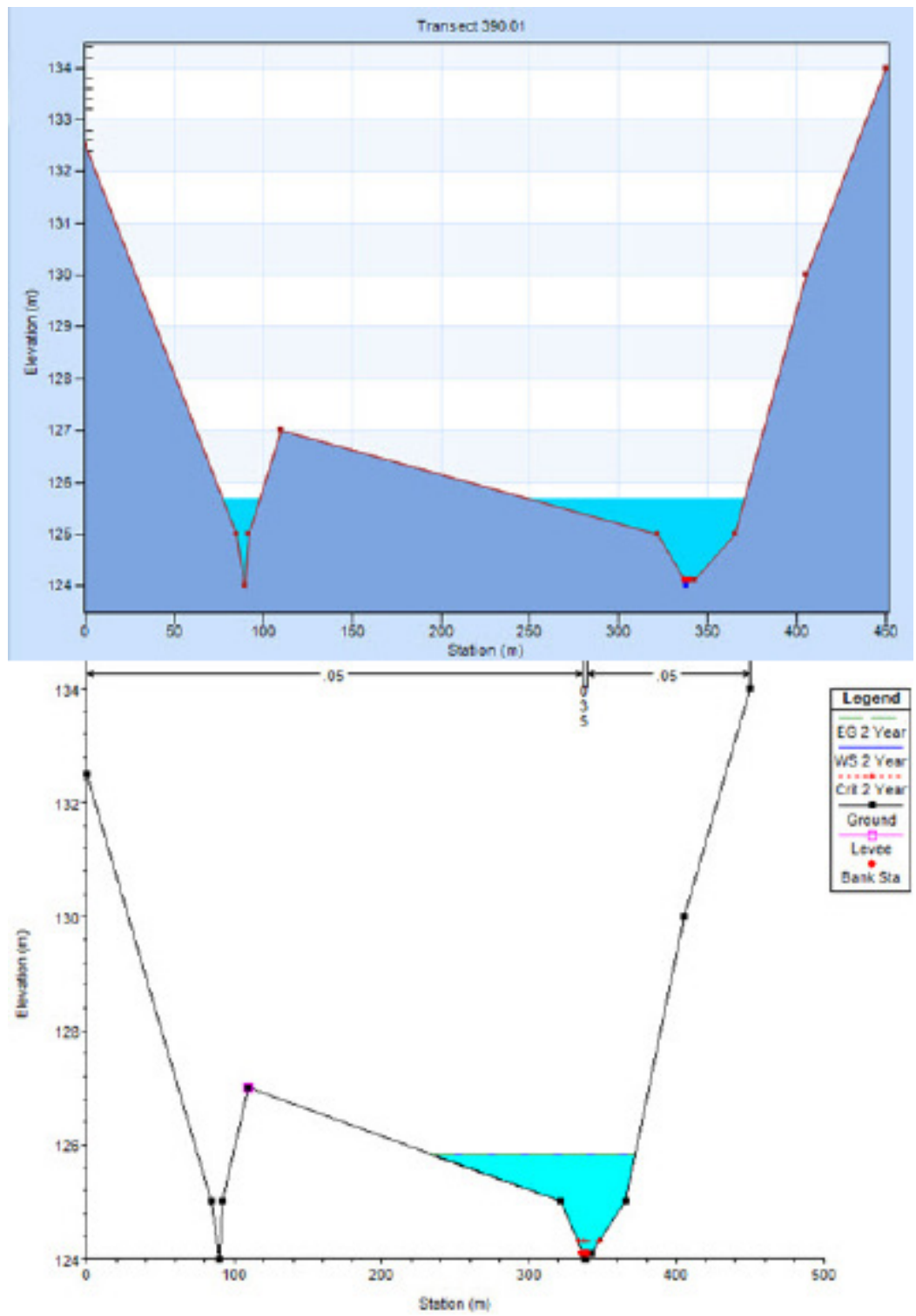

Figure 5.8 Transect 390.01 peak flow comparison between SWMM5 (top) and HEC-RAS (bottom). 
In a river network, there can be localized depressions that are not part of the river channel, but which are included in the cross section or transect. In HECRAS, these areas can be defined with levees at a set elevation or by defining the area as being ineffective flow.

In SWMM5, the transect depth of flow is calculated using the elevations defined in the cross section. SWMM5 does not model levees or ineffective flow, which results in the secondary channel being shown to inundate at the same time as the main channel.

Figure 5.8 above illustrates a scenario where there are two channels within the cross section. The first transect was taken from PCSWMM and shows the secondary channel being inundated with flow at the same elevation as the main channel. The second cross section was taken from HEC-RAS and has a levee shown in pink. The levee prevents flow from entertaining the secondary channel until the elevation of the levee has been exceeded.

\subsection{Expansion and Contraction Loss Coefficients}

In HEC-RAS, contraction and expansion coefficients are assigned in the cross sectional data, but these are not automatically imported into SWMM5.

In the basin 39A HEC-RAS model, the contraction and expansion coefficients were 0.3 and 0.5 . To account for the system losses in SWMM5, the sum of the assigned roughness coefficients (0.8) was assigned as an average loss to all SWMM5 conduits, reducing the water surface elevation (WSE) differences between the two models. A further reduction in the WSE was observed when an average loss coefficient of 0.6 was applied.

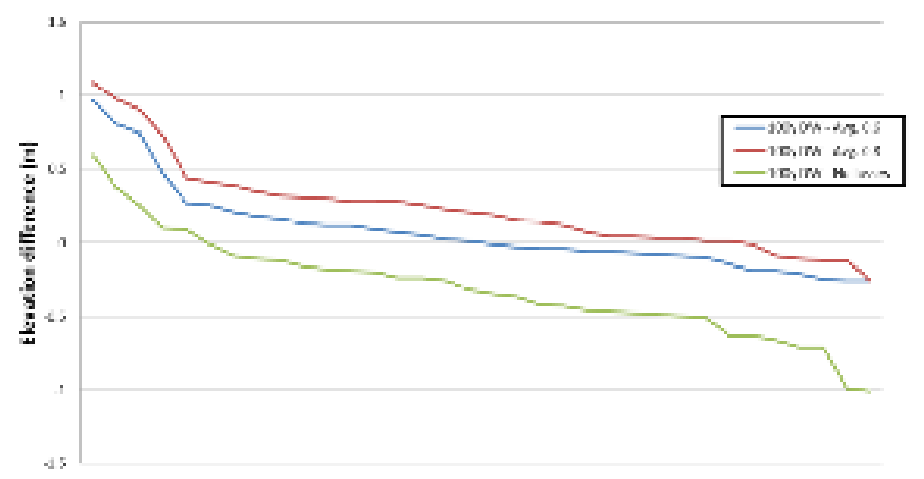

Figure 5.9 Difference in elevation between SWMM5 and HEC-RAS; 100 y assigned average loss comparison. 
Figure 5.9 above shows the differences in WSE for three scenarios. The $y$-axis is the elevation difference between SWMM5 and HEC-RAS results. The green line represents the elevation discrepencies when SWMM5 was run with no losses, while the blue and red lines represent the elevation discrepancies when average loss coefficients of 0.6 and 0.8 were applied.

\subsection{Water Surface Elevation Comparisons}

To determine if SWMM5 could simulate comparable results computed by HEC-RAS, surface elevation profiles were plotted using the $100 \mathrm{y}$ design event. This exercise was not done to calibrate to HEC-RAS results, but rather to determine if SWMM5 was able to produce comparable results with minimal adjustment.

The largest HGL discrepancies were observed at the upstream location of the bridges. Figure 5.10 compares the two computed peak water levels, where the blue filled area is the SWMM5 generated results and the red line markers represent the HEC-RAS WSE results.

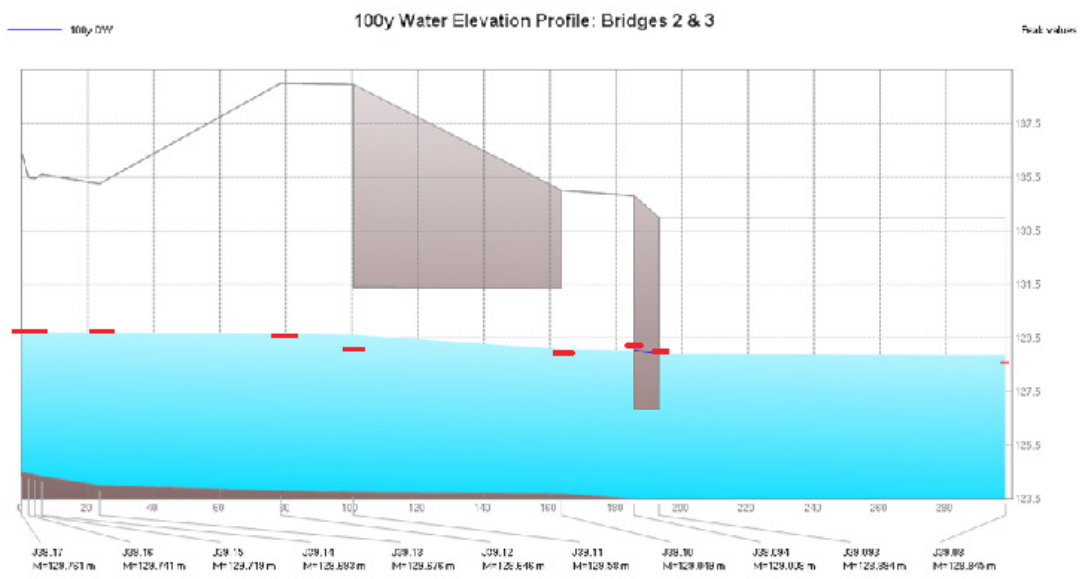

Figure 5.10100 y water surface elevation profile at bridge 39.105.

To generate the results computed from HEC-RAS, the average loss coefficient was increased at the upstream bridge location. Figure 5.11 shows the new SWMM5 computed water surface elevation as well as the original SWMM5 results displayed in green. It was observed that by increasing the average loss coefficient at the upstream conduit of a bridge, the water surface elevation was better matched to the HEC-RAS computed results. 


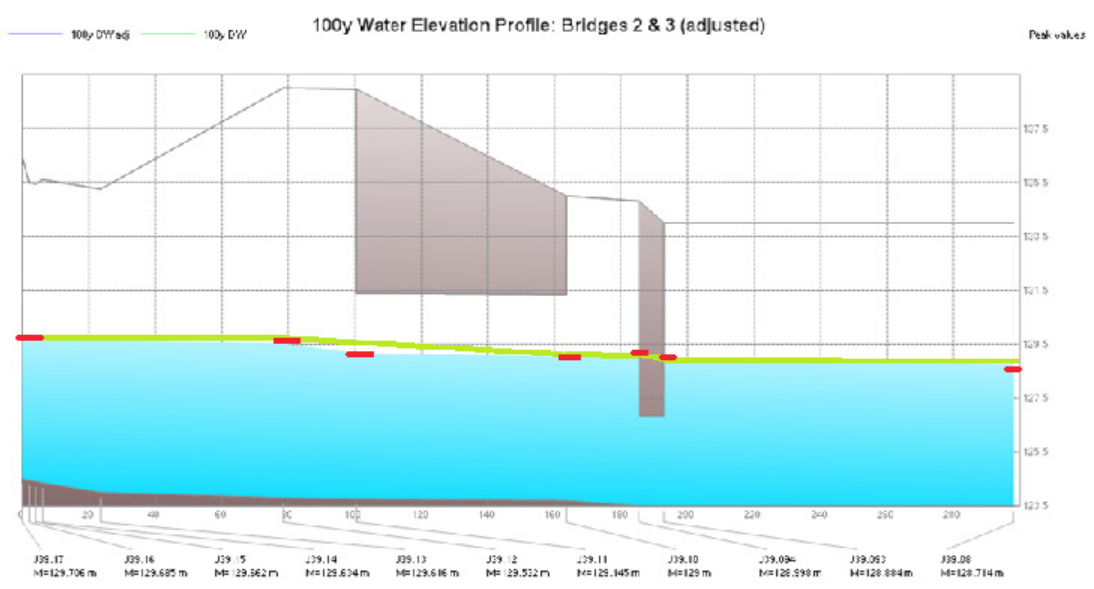

Figure 5.11100 y water surface elevation profile at bridge 39.105 adjusted.

\subsection{Discussion and Conclusions}

HEC-RAS and its predecessor HEC-2 are hydraulic modeling software packages which are widely accepted for use in flood line mapping studies and other river or stream analyses. SWMM5 models have an advantage in being able to model the hydraulics and hydrology of a watershed and are also able to represent complex river and stream systems using dynamic wave routing.

PCSWMM, a decision support system for SWMM5, now includes a recently developed HEC-RAS importer that is able to convert HEC-RAS models into SWMM5 which allows for the leveraging of previous HEC-RAS model data.

A comparison study was completed to determine if a steady state HECRAS model could produce similar water surface elevations to a SWMM5 model generated by using a HEC-RAS model imported into SWMM5. The HEC-RAS model was imported into two separate SWMM5 projects, one set up for kinematic wave routing and the second set up to import the HEC-RAS model using dynamic wave routing.

SWMM5 was able to produce similar results to HEC-RAS using dynamic wave routing without adjustment. However, uniformly changing the average loss coefficients showed that the computed water surface elevation differences could be reduced. SWMM5 was not able to replicate the water surface elevations using kinematic wave routing, due to the limitations associated with kinematic routing in SWMM5. 
Other studies performed similar comparisons and suggest that the water surface elevation differences between two software packages result from differences in computation of the bridge losses and channel roughness. A study completed by Todd (2004) compared the water surface elevations using HECRAS and MIKE 11 unsteady flow models. He found that the computed difference in water surface elevation could be accounted for by adjusting the Manning's roughness coefficient.

Another study completed by the U.S. Army Corps of Engineers (1995) compared the water surface elevation for HEC-RAS, HEC-2 and WSPRO (water surface profile computational model). Discrepancies were also found because of how the water elevations were computed near bridge structures due to contraction and expansion differences. However, the differences were not considered significant.

In this study, the HEC-RAS water surface elevations were replicated by adjusting the average loss coefficients. However, the overall differences in the computed water surface elevations between the dynamic SWMM5 model and the original HEC-RAS model were not significant.

\section{References}

Federal Emergency Management Agency. 2002. Floodplain Modeling Manual - HECRAS Procedures for HEC-2 Modelers. Dewberry \& Davis LLC. Washington, DC.

James, William, Lewis A. Rossman, W. Robert C. James. 2011. User's Guide to SWMM5, 13th Edn. CHI, Guelph. ISBN: 978-0-9808853-5-4.

Rossman, Lewis A. 2008. Storm Water Management Model User's Manual Version 5.0. Pub. Water Supply and Water Resources Division, National Risk Management Research Laboratory, Cincinnati, $\mathrm{OH}$.

Todd, H. 2004. Comparison of HEC-RAS and MIKE 11 Unsteady Flow Modeling for the Tillamook Valley. World Water Congress, Salt Lake City, UT. ASCE Conf. Proc. ISBN 0-7844-0737-1.

U.S. Army Corps of Engineers. 1995. A Comparison of the One-Dimensional Bridge Hydraulic Routines from HEC-RAS, HEC-2 and WSPRO (RD-41, 28 pp).

U.S. Army Corps of Engineers. 2010. HEC-RAS River analysis system applications guide. Version 4.1, Davis, CA. 
